JGRADASI TEKnIK SIPIL 


\section{JURNAL GRADASI TEKNIK SIPIL POLITEKNIK NEGERI BANJARMASIN}

Jurnal Gradasi Teknik Sipil diterbitkan oleh Pusat Penelitian dan Pengabdian Kepada Masyarakat Politeknik Negeri Banjarmasin. Ruang lingkup makalah meliputi Bidang Teknik dan Manajemen dengan konsentrasi Bidang Transportasi, Geoteknik, Struktur, Keairan dan Manajemen Konstruksi. Isi makalah dapat berupa penyajian isu aktual di bidang Teknik Sipil, review terhadap perkembangan penelitian, pemaparan hasil penelitian, dan pengembangan metode, aplikasi, dan prosedur di bidang Teknik Sipil. Makalah ditulis mengikuti panduan penulisan.

\section{Penanggung Jawab}

Nurmahaludin, ST, MT.

\section{Dewan Redaksi}

Ketua :

Anggota : Riska Hawinuti, ST, MT.

Nurfitriah, S.Pd, MA.

Ir. Rusliansyah, M.Sc.

\section{Reviewer}

Dr. Ir. Yanuar Jarwadi Purwanto, MS. (Institut Pertanian Bogor)

Dr. Ir. Achmad Rusdiansyah, MT. (Universitas Lambung Mangkurat)

Dr. Ir. M. Azhar, M. Sc. (Institut Sains dan Teknologi Nasional)

Dr. Ir. Endang Widjajanti, MT. (Institut Sains dan Teknologi Nasional)

Joni Irawan, ST, MT. (Politeknik Negeri Banjarmasin)

Yusti Yudiawati, ST, MT. (Politeknik Negeri Banjarmasin)

\section{Editing dan Tata Bahasa}

Nurfitriah, S.Pd., MA.

\section{Desain dan Tata Letak}

Abdul Hafizh Ihsani

\section{Alamat Redaksi}

Jurusan Gradasi Teknik Sipil Politeknik Negeri Banjarmasin, Jl. Brigjen H. Hasan Basri 70123 Banjarmasin Telp/Fax 0511-3307757; Email: gradasi.tekniksipil@poliban.ac.id 


\section{JURNAL GRADASI TEKNIK SIPIL}

\section{DAFTAR ISI}

Perencanaan Campuran Lapis Aspal Beton Permukaan Dengan Asbuton Butir Sebagai Filler ...( 1 - 9 )

Surat, Rifanie Gazalie, Pazilatul Mumamiroh

Pengaruh Keberadaan Pasar Sungai Lulut Terhadap Kinerja Jalan Martapura Lama KM. 05 ...( 10 - 19)

\section{Riska Hawinuti}

Analisis Perbandingan Biaya Penggunaan Perancah Kayu Galam Dan Perancah Besi (Scaffolding) ...( $20-32)$ Aunur Rafik, Rinova Firman Cahyani

Tinjauan Debit Andalan untuk Irigasi di Kecamatan Sungai Tabuk Kabupaten Banjar ...( $33-43)$

Fakhrurrazi, Herliyani Farial Agoes, Desi Anggeriyani

Ekosemen Sebagai Media Perekat Pengganti Semen Untuk Beton ...( 44 - 51 ) Marhadi Sastra, Juli Ardita Pribadi R

Pengaruh Posisi, Jumlah Layer Dan Mutu Kayu Terhadap Balok Laminasi Kayu Mahang Dan Kayu Meranti ...( 52 - 60 )

\section{Indriyani Puluhulawa}

Visualisasi Dan Identifikasi Pola Retak Dinding Bata Akibat Penurunan Pondasi Struktur Bangunan Di Kota Banjarmasin ...( 61 - 68 )

\section{Darmansyah Tjitradi, Eliatun}

Pengembangan Perumahan Dengan Desain Konstruksi Dilahan Basah Pada Wilayah Kota Banjarmasin Menggunakan Riset Operasi ...( 69 - 75 )

\section{Eliatun, Darmansyah Tjitradi}




\title{
Pengaruh Keberadaan Pasar Sungai Lulut Terhadap Kinerja Jalan Martapura Lama KM. 05
}

\author{
Riska Hawinuti $^{1 *}$ \\ ${ }^{1}$ Dosen Jurusan Teknik Sipil Politeknik Negeri Banjarmasin \\ e-mail: *1 riska_hawinuti@yahoo.co.id (corresponding author)
}

\begin{abstract}
Abstrak
Jalan Martapura Lama merupakan jalur alternative penghubung Kota Banjarmasin, Martapura dan Banjarbaru yang berada dibawah pemerintahan administratif Kabupaten Banjar. Keberadaan Pasar Sungai Lulut di Kilometer 05 konsisten menyebabkan daerah tersebut mengalami kemacetan di jam sibuk pagi, siang dan sore. Tujuan penelitian ini adalah untuk mengetahui dampak aktivitas pasar terhadap kinerja ruas Jalan Martapura Lama KM 05 yang dinyatakan dengan derajat kejenuhan (DS) dan nilai tingkat pelayanan jalannya.

Metode pengambilan data primer adalah dengan melakukan survey lalu lintas dan pengukuran kondisi geometrik di lapangan secara manual pada Hari Selasa sampai Kamis, 06-08 Februari 2018 pada jam sibuk pagi (pukul 07.00-08.00 WITA), jam sibuk siang (pukul 12.00-14.00 WITA) dan jam sibuk sore (pukul 16.00-18.00 WITA) sedangkan data sekunder diperoleh dari internet dengan perhitungan mengacu pada MKJI 1997.

Dari hasil perhitungan dapat disimpulkan dampak aktivitas pasar terhadap kinerja ruas Jalan Martapura Lama KM 05 yang dinyatakan dengan derajat kejenuhan (DS) dan nilai tingkat pelayanan jalan diperoleh nilai DS terbaik sebesar 0,68 dengan tingkat pelayanan jalan adalah $C$ pada jam sibuk sore hari Kamis dan nilai DS terburuk sebesar 1,34 dengan tingkat pelayanan F pada jam sibuk pagi hari Rabu. Dengan Total Frekuensi Berbobot Kejadian dan Kelas Hambatan Samping sebesar 571 frekuensi, hambatan terbesar adalah kendaraan masuk dan keluar lahan di samping jalan (EEV) sebesar 446 kejadian pada Hari Selasa pada jam sibuk pagi.
\end{abstract}

Kata kunci-Jam sibuk, Tingkat Pelayanan Jalan, Hambatan Samping

\begin{abstract}
Jalan Martapura Lama is an alternative road connecting Banjarmasin, Martapura and Banjarbaru city and it is under the administration of Banjar Regency. The existence of Sungai Lulut Market in Kilometer 05 consistently causing congestion to the area, especially during peak hours. The purpose of this study is to determine the impact of market activities on the performance of Jalan Martapura Lama KM 05 indicated by the degree of saturation (DS) and the value of the level of road service.

The method of primary data collection was by conducting traffic surveys and measuring geometric conditions in the site manually on Tuesday to Thursday, 06-08 February 2018 during the morning rush hour (07.00-08.00 a.m), the noon hour $(12.00-14.00 \mathrm{p.m})$ and afternoon rush hour $(16.00$ to $18.00 \mathrm{p.m})$ while the secondary data was obtained from the internet. The calculation refers to Indonesian Highway Capacity Manual (MKJI) 1997.

From the calculation results it can be concluded that the impact of market activities on the performance of Jalan Martapura Lama KM 05 indicated by the degree of saturation (DS) and the value of road level of service with the optimum DS is 0,68 with the value of level of road service is $C$ on Thursday's afternoon rush hour and the minimum DS is 1.34 with the value of level of road service is $F$ on Wednesday's morning rush hour. With a total frequency of occurrences and side friction class of 571 frequencies, the maksimum friction is incoming and outgoing vehicles on area alongside roads (EEVs) of 446 occurrences on Tuesday in the morning rush hour.
\end{abstract}

Keywords—Rush Hour, Level of Road Service, Side Friction 


\section{PENDAHULUAN}

Jalan adalah seluruh bagian jalan termasuk bangunan pelengkap dan perlengkapannya yang diperuntukkan bagi lalu lintas umum, yang berada pada permukaan tanah, di atas tanah, di bawah permukaan tanah dan/ atau air serta di atas permukaan air, kecuali jalan rel dan jalan kabel (UU RI No. 22 Tahun 2009). Normalnya, kondisi jalan harus bebas dari berbagai hal yang menyebabkan gangguan kenyamanan pengguna jalan tersebut. Hambatan samping akan berpengaruh terhadap kapasitas ruas jalan. Salah satu bentuk hambatan samping yang sering dijumpai adalah aktivitas pasar yang menggunakan bahu serta badan jalan. Lebar jalan yang tersita oleh aktivitas pasar tentu mengurangi kemampuan jalan tersebut dalam menampung arus kendaraan yang lewat, atau dengan kata lain terjadi penurunan kapasitas ruas jalan (Tamin, 2000).

Pasar Sungai Lulut merupakan jenis pasar tradisional yang telah berdiri selama puluhan tahun dan menjadi tempat perputaran perekonomian yang cukup besar untuk daerah Kelurahan Sungai Lulut Kabupaten Banjar. Posisi pasar yang tepat berada dipinggir jalan alternatif penghubung antar kota Banjarmasin, Martapura dan Banjarbaru, membuat badan jalan turut menjadi lokasi parkir sementara sekaligus tempat berjualan bagi sebagian pedagang. Selain pasar, keberadaan komplek perumahan penduduk, sekolah dan rendahnya kemampuan penyediaan prasarana jaringan jalan, sementara tingkat arus kendaraan semakin meningkat, menyebabkan ruas jalan tersebut mengalami kemacetan yang cukup parah di jam sibuk pagi saat berangkat kerja dan jam sibuk sore, saat jam masyarakat pulang dari tempat bekerja.

Kemacetan adalah kondisi dimana arus lalulintas yang lewat pada ruas jalan yang ditinjau melebihi kapasitas rencana jalan tersebut yang mengakibatkan kecepatan bebas ruas jalan tersebut mendekati atau $0 \mathrm{~km} / \mathrm{jam}$ sehingga menyebabkan terjadinya antrian. Pada saat terjadinya kemacetan, nilai derajat kejenuhan pada ruas jalan akan ditinjau dimana kemacetan akan terjadi bila nilai derajat kejenuhan mencapai lebih dari 0,75 (MKJI, 1997). Hal tersebut mendasari penulis untuk melakukan penelitian dengan judul "Pengaruh Keberadaan
Pasar Tradisional Terhadap Kinerja Jalan Martapura Lama KM.05, Kabupaten Banjar”.

Tujuan penelitian ini adalah untuk mengetahui dampak aktivitas pasar terhadap kinerja ruas Jalan Martapura Lama KM 05 yang dinyatakan dengan derajat kejenuhan (DS) dan nilai tingkat pelayanan jalannya. Manfaat Penelitian ini antara lain untuk memberi masukan kepada pihak terkait mengenai perbaikan ruang jalan tersebut di masa akan datang dan bahan tambahan pembelajaran di bidang transportasi bagi mahasiswa dan pemanfaat lainnya.

Menurut MKJI 1997, karakteristik utama jalan yang akan mempengaruhi kapasitas dan kinerjanya apabila dibebankan pada suatu badan jalan antara lain kondisi geometrik jalan; arus, komposisi dan pemisahan arah; pengendalian lalu lintas; aktivitas hambatan samping; fungsi jalan dan tata guna lahan serta pengemudi dan populasi kendaraan.

Nilai arus lalu-lintas (Q) mencerminkan komposisi lalu-lintas, dengan menyatakan arus dalam satuan mobil penumpang (smp). Semua nilai arus lalu-lintas (per arah dan total) dikonversikan menjadi satuan mobil penumpang (smp) dengan menggunakan ekivalensi mobil penumpang (emp) yang diturunkan secara empiris untuk tipe kendaraan berikut (1) Kendaraan ringan disingkat LV, emp selalu 1,0 meliputi mobil penumpang, minibus, truk pick-up dan jeep, (2) Kendaraan berat menengah disingkat MHV meliputi truk dua gandar dan bus kecil, (3) Bus besar disingkat LB, (4) Truk besar disingkat LT meliputi truk tiga gandar dan truk gandengan, (5) Sepeda motor disingkat MC.

Berikut adalah ekivalensi kendaraan penumpang untuk jalan dua jalur dua arah tak terbagi, seperti yang terlihat pada Tabel 1 berikut.

\begin{tabular}{|c|c|c|c|c|c|c|c|}
\hline \multirow{4}{*}{$\begin{array}{c}\text { Tipe } \\
\text { Aliny emen }\end{array}$} & \multirow{4}{*}{$\begin{array}{c}\text { Arus } \\
\text { Total } \\
\text { (kend/jam) }\end{array}$} & \multicolumn{6}{|c|}{ emp } \\
\hline & & \multirow{3}{*}{ MHV } & \multirow{3}{*}{ LB } & \multirow{3}{*}{ LT } & \multicolumn{3}{|c|}{ MC } \\
\hline & & & & & \multicolumn{3}{|c|}{\begin{tabular}{|c} 
Lebar Jalur Lalu lintas \\
$(\mathrm{m})$
\end{tabular}} \\
\hline & & & & & $<6 \mathrm{~m}$ & $6-8 \mathrm{~m}$ & $>8 \mathrm{~m}$ \\
\hline \multirow[t]{4}{*}{ Datar } & 0 & 1,2 & 1,2 & 1,8 & 0,8 & 0,6 & 0,4 \\
\hline & 800 & 1,8 & 1,8 & 2,7 & 1,2 & 0,9 & 0.6 \\
\hline & 1350 & 1,5 & 1,6 & 2,5 & 0,9 & 0,7 & 0,6 \\
\hline & $\geq 1900$ & 1,3 & 1,5 & 2,5 & 0,6 & 0,5 & 0,4 \\
\hline \multirow[t]{4}{*}{ Bukit } & 0 & 1,8 & 1,6 & 5,2 & 0,7 & 0,5 & 0,3 \\
\hline & 650 & 2,4 & 2,5 & 5,0 & 1,0 & 0,8 & 0,5 \\
\hline & 1100 & 2,0 & 2,0 & 4,0 & 0,8 & 0,6 & 0.4 \\
\hline & $\geq 1600$ & 1,7 & 1,7 & 3,2 & 0,5 & 0,4 & 0,3 \\
\hline \multirow[t]{4}{*}{ Gunung } & & 3,5 & 2,5 & 6,0 & 0,6 & 0,4 & 0,2 \\
\hline & 450 & 3,0 & 3,2 & 5,5 & 0,9 & 0,7 & 0,4 \\
\hline & 900 & 2,5 & 2,5 & 5,0 & 0,7 & 0,5 & 0,3 \\
\hline & $\geq 1350$ & 1,9 & 2,2 & 4,0 & 0,5 & 0,4 & 0,3 \\
\hline
\end{tabular}


Hambatan samping adalah pengaruh kegiatan di samping ruas jalan terhadap kinerja lalu lintas, misalnya pejalan kaki (bobot 0,6) penghentian kendaraan umum atau kendaraan lainnya (bobot $=$ $0,8)$, kendaraan masuk dan keluar lahan di samping jalan $($ bobot $=1,0)$ dan kendaraan lambat $($ bobot $=$ $0,4)$. Berikut adalah kelas hambatan samping seperti terlihat pada Tabel 2 berikut.

\begin{tabular}{|c|c|c|c|}
\hline \multirow{2}{*}{$\begin{array}{c}\text { Frekuensi berbobot } \\
\text { dan Kejadian (dua } \\
\text { sisi) } \\
<50\end{array}$} & \multirow{2}{*}{$\begin{array}{c}\text { Kondisi Khas } \\
\begin{array}{c}\text { Pedalaman, pertanian atau tidak } \\
\text { berkembang; tanpa kegiatan }\end{array}\end{array}$} & \multicolumn{2}{|c|}{$\begin{array}{c}\text { Kelas } \\
\text { Hambatan } \\
\text { Samping }\end{array}$} \\
\hline & & $\begin{array}{l}\text { Sangat } \\
\text { Rendah }\end{array}$ & VL \\
\hline $50-149$ & $\begin{array}{c}\text { Pedalaman, beberapa bangunan dan } \\
\text { kegiatan disamping jalan }\end{array}$ & Rendah & $\mathrm{L}$ \\
\hline $150-249$ & Desa, kegiatan dan angkutan lokal & Sedang & $\mathrm{M}$ \\
\hline $250-349$ & Desa, beberapa kegiatan pasar & Tinggi & $\mathrm{H}$ \\
\hline$>350$ & $\begin{array}{c}\text { Hampir perkotaan, pasar/ kegiatan } \\
\text { perdagangan }\end{array}$ & $\begin{array}{l}\text { Sangat } \\
\text { Tinggi }\end{array}$ & $\mathrm{VH}$ \\
\hline
\end{tabular}

Sumber: MKJI 1997

Kapasitas didefinisikan sebagai arus maksimum yang dapat dipertahankan persatuan jam yang melewati suatu titik di jalan dalam kondisi yang ada. Untuk jalan dua-lajur dua-arah, kapasitas didefinisikan untuk arus dua-arah (kedua arah kombinasi), tetapi untuk jalan dengan banyak lajur, arus dipisahkan per arah perjalanan dan kapasitas didefinisikan per lajur. Persamaan dasar untuk penentuan kapasitas (C) adalah sebagai berikut:

$$
\mathrm{C}=\mathrm{C}_{0} \times \mathrm{FC}_{\mathrm{W}} \times \mathrm{FC}_{\mathrm{Sp}} \times \mathrm{FC}_{\mathrm{SF}}
$$

Dimana:

$\mathrm{C}=$ kapasitas $(\mathrm{smp} / \mathrm{jam})$

$\mathrm{CO}=$ kapasitas dasar (smp/jam)

$\mathrm{FCW}=$ faktor penyesuaian lebar jalan

$\mathrm{FCSP}=$ faktor penyesuaian pemisahan arah (hanya untuk jalan tak terbagi)

FCSF = faktor penyesuaian hambatan samping dan bahu jalan

Berikut adalah kapasitas dasar (CO) pada jalan luar kota 2-jalur 2-arah tak-terbagi (2/2 UD), faktor penyesuaian kapasitas akibat lebar jalur lalulintas (FCW) ,faktor penyesuaian kapasitas akibat pemisahan arah (FCSP), dan faktor penyesuaian kapasitas akibat hambatan samping (FCSF) seperti yang terlihat pada Tabel 3 sampai 6 berikut.
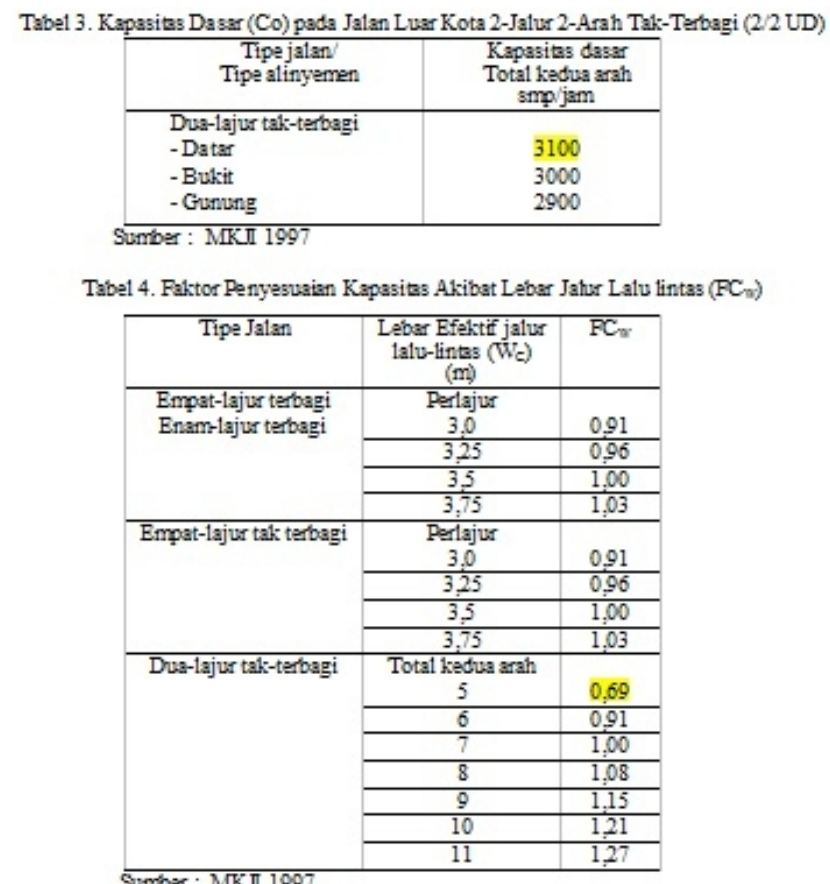

Tabel 5. Faktor Penyesuaian Kapasitas Akibat Pemisahan Arah ( $\left.\mathrm{CC}_{2 y}\right)$

\begin{tabular}{|l|l|c|c|c|c|c|}
\hline \multicolumn{2}{|c|}{$\begin{array}{l}\text { Pemisahan arah } \\
\text { SP \%-\% }\end{array}$} & $50-50$ & $55-45$ & $60-40$ & $65-35$ & $70-30$ \\
\hline \multirow{2}{*}{ FC $_{2 \pi}$} & $\begin{array}{l}\text { Dua- } \\
\text { 1ajur 2/2 }\end{array}$ & 1,00 & 0,97 & 0,94 & 0,91 & 0,88 \\
\cline { 2 - 7 } & $\begin{array}{l}\text { Empat- } \\
\text { 1ajur 4/2 }\end{array}$ & 1,00 & 0,975 & 0,95 & 0,925 & 0,90 \\
\hline Sumber: MKI 1997 & & & &
\end{tabular}

Tabel 6. Faktor Penyesuaian Kapasitas Akibat Hambatan Samping ( $\left.\mathrm{FC}_{2 \pi}\right)$

\begin{tabular}{|c|c|c|c|c|c|}
\hline \multirow[t]{3}{*}{$\begin{array}{l}\text { Tipe } \\
\text { Jalan }\end{array}$} & \multirow{3}{*}{$\begin{array}{c}\text { Kelas } \\
\text { hambatan } \\
\text { samping }\end{array}$} & \multicolumn{4}{|c|}{$\begin{array}{l}\text { Faktor penyesuaian akibat } \\
\text { hambatan samping }\left(\mathrm{FC}_{g z}\right)\end{array}$} \\
\hline & & \multicolumn{4}{|c|}{ Labar bahu efektif $\mathrm{W}_{\mathrm{s}}$} \\
\hline & & $\leq 0,5$ & 1,0 & 1,5 & $\geq 2,0$ \\
\hline \multirow[t]{5}{*}{$4 / 2 \mathrm{D}$} & $\overline{V L}$ & 099 & 1.00 & 1.01 & 1.03 \\
\hline & I & 0.96 & 097 & 099 & 1.01 \\
\hline & $\bar{M}$ & 093 & 096 & 096 & 099 \\
\hline & $\mathrm{H}$ & 090 & 0,92 & 0,95 & 0,97 \\
\hline & VH & 0.88 & 0,90 & 093 & 096 \\
\hline \multirow[t]{2}{*}{$2 / 2 \mathrm{UD}$} & $\overline{V L}$ & 097 & 099 & 1.00 & 1.02 \\
\hline & $\mathrm{L}$ & 0,93 & 0,95 & 0,97 & 1,00 \\
\hline \multirow[t]{3}{*}{$4 / 2 \mathrm{UD}$} & $\overline{\mathrm{M}}$ & 0,88 & 091 & 0,94 & 0,98 \\
\hline & $\mathrm{H}$ & 0,84 & 0,87 & 091 & 0,95 \\
\hline & VH & 0,80 & 0,83 & 0,88 & 0,93 \\
\hline
\end{tabular}

Derajat kejenuhan didefinisikan sebagai rasio arus terhadap kapasitas, digunakan sebagai faktor kunci dalam penentuan perilaku lalu-lintas pada suatu simpang dan juga segmen jalan. Nilai derajat kejenuhan menunjukkan apakah segmen jalan akan mempunyai masalah kapasitas atau tidak. MKJI 1997 mensyaratkan untuk perencanaan harus memastikan bahwa nilai Derajat Kejenuhan $<0,75$. 
Persamaan dasar untuk menghitung derajat kejenuhan (DS) adalah sebagai berikut.

$$
\mathrm{DS}=\frac{\mathrm{Q}}{\mathrm{C}}
$$

$$
\begin{aligned}
& \text { Dimana: } \\
& \text { DS = Derajat Kejenuhan } \\
& \text { Q }=\text { Volume Arus Lalu Lintas (smp/ jam) } \\
& \text { C } \quad \text { Kapasitas (smp/ jam) }
\end{aligned}
$$

Kecepatan tempuh sebagai ukuran utama kinerja segmen jalan, merupakan masukan yang penting bagi biaya pemakai jalan dalam analisa ekonomi. Kecepatan tempuh didefinisikan sebagai kecepatan rata-rata ruang dari kendaraan ringan sepanjang segmen jalan dan dapat dihitung dengan persamaan berikut.

$$
V=\frac{L}{T T}
$$

Dimana:

$\mathrm{V}$ = kecepatan ruang rata-rata kend. ringan ( $\mathrm{km} / \mathrm{jam})$

$\mathrm{L} \quad=$ panjang segmen $(\mathrm{km})$

$\mathrm{TT}=$ waktu tempuh rata-rata dari kendaraan ringan sepanjang segmen (jam)

Hubungan antara kecepatan dan volume jalan perlu diketahui karena kecepatan dan volume merupakan aspek penting dalam menentukan tingkat pelayanan jalan. Apabila volume lalu lintas pada suatu jalan meningkat dan tidak dapat mempertahankan suatu kecepatan konstan, maka pengemudi akan mengalami kelelahan dan tidak dapat memenuhi waktu perjalan yang direncanakan.

Menurut Warpani (2002), tingkat pelayanan adalah ukuran kecepatan laju kendaraan yang dikaitkan dengan kondisi dan kapasitas jalan. Secara status (wewenang pembinaannya) menurut PP No. 34 Tahun 2006 tentang Jalan dan Peraturan Daerah Kabupaten Banjar Nomor 3 Tahun 2013 tentang Rencana Tata Ruang Wilayah Kabupaten Banjar Tahun 2013-2032, Jalan Martapura (Martapura - Sungai Lulut) adalah berstatus Jalan Kabupaten-Jalan Kolektor Primer K2 dan K3 ,

\begin{tabular}{|c|c|}
\hline $\begin{array}{l}\text { Tingkat } \\
\text { Pelayanan }\end{array}$ & Karakteristik Operasi Terkait \\
\hline A & $\begin{array}{l}\text { 1. Kecepatan lalu lintas } \geq 100 \mathrm{~km} / \mathrm{jam} \\
\text { 2. Volume lalu lintas sekitar } 30 \% \text { dari kapasitas } \\
\text { (yaitu } 600 \mathrm{smp} / \mathrm{jam} / \text { ajur). }\end{array}$ \\
\hline B & $\begin{array}{l}\text { 1. Awal dari kondisi arus stabil } \\
\text { 2. Kecepatan lalu lintas sekitar } 90 \mathrm{~km} / \mathrm{jam} \\
\text { 3. Volume lalu lintas tidak melebihi } 50 \% \\
\text { kapasitas (yaitu } 1000 \mathrm{smp} / \mathrm{jam} / \text { ajur) }\end{array}$ \\
\hline $\mathrm{C}$ & $\begin{array}{l}\text { 1. Arus stabil } \\
\text { 2. Kecepatan lalu lintas } \geq 75 \mathrm{~km} / \mathrm{jam} \\
\text { 3. Volume 1alu lintas tidak melebihi } 75 \% \\
\text { kapasitas (yaitu } 1500 \mathrm{smp} / \mathrm{jam} / \text { lajur) }\end{array}$ \\
\hline $\mathrm{D}$ & $\begin{array}{l}\text { 1. Mendekati arus tidak stabil } \\
\text { 2. Kecepatan lalu lintas sekitar } 60 \mathrm{~km} / \mathrm{jam} \\
\text { 3. Volume lalu lintas sampai } 90 \% \mathrm{kapasitas} \text { (yaitu } \\
1800 \mathrm{smp} / \mathrm{jam} / \text { ajur) }\end{array}$ \\
\hline $\mathrm{E}$ & $\begin{array}{l}\text { 1. Arus pada tingkat kapasitas (yaitu } 2000 \\
\text { smp/jam/lajur) } \\
\text { 2. Kecepatan lalu lintas sekitar } 50 \mathrm{~km} / \mathrm{jam}\end{array}$ \\
\hline $\mathrm{F}$ & $\begin{array}{l}\text { 1. Arus tertahan, kondisi terhambat (congested) } \\
\text { 2. Kecepatan lalu lintas }<50 \mathrm{~km} / \mathrm{jam}\end{array}$ \\
\hline
\end{tabular}

sehingga untuk menjelaskan tentang tingkat pelayanan dan karakteristik jalan, dengan batas lingkup V/C Ratio dapat dilihat pada Tabel 7 berikut.

Tabel 7. Tingkat Pelayanan dan Karakteristik Jalan untuk Jalan Kolektor Primer

Sumber : Peraturan Menteri Perhubungan Nomor: KM 14 Tahun 2006 tentang Manajemen dan Rekayasa Lalu Lintas di Jalan

\section{METODE PENELITIAN}

\section{A. Lokasi Penelitian}

Penelitian dilaksanakan di Ruas Jalan Martapura Lama KM.05 Kelurahan Sungai Lulut Kabupaten Banjar, Kalimantan Selatan. Ruas jalan yang diamati adalah sepanjang $400 \mathrm{M}$. Fungsi jalan adalah Jalan Kolektor Primer, alinyemen datar dan tipe jalan adalah dua lajur dua arah tidak terbagi (2/2 UD). Lokasi penelitian dapat dilihat pada Gambar 1 berikut.

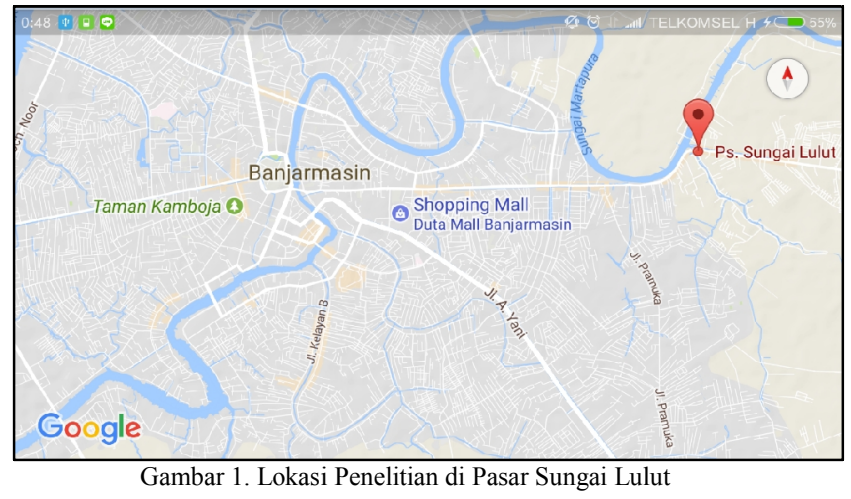


B. Instrumen Penelitian

Peralatan yang digunakan adalah alat tulis, handphone android dengan aplikasi traffic counting, pencatat waktu (stop watch), meteran standard dan oddometer, jam tangan sebagai penunjuk waktu selama pelaksanaan survey, satu unit kendaraan roda dua untuk mengukur kecepatan rata-rata kendaraan yang lewat, laptop sebagai alat untuk menghitung dan mengolah data.

\section{Prosedur Pengambilan Data}

Data yang diambil adalah data primer yang diambil langsung dengan cara survey langsung di lapangan secara manual pada waktu yang ditentukan dan data sekunder yang diperoleh dari pihak ketiga (internet).

1. Data Primer: Terdiri dari data Geometrik Ruas Jalan, Arus Lalu Lintas dan Hambatan Samping. Geometrik ruas jalan, antara lain: alinyemen horizontal dan pengembangan di samping jalan; kelas jarak pandang; alinyemen vertikal; tipe alinyemen; penampang melintang jalan; kondisi permukaan jalan dan kondisi pengaturan lalu lintas. Arus lalu lintas meliputi jumlah kendaraan berdasarkan kelasnya selama jam sibuk yang ditentukan. Hambatan samping (per jam per 200 meter pada kedua sisi segmen yang ditinjau), antara lain: jumlah pejalan kaki dan penyeberang jalan; jumlah penghentian kendaraan dan gerakan parkir; jumlah kendaraan bermotor yang keluar masuk lahan samping jalan dan jalan samping; arus kendaraan lambat dari pergerakan sepeda, becak, delman, pedati dan kendaraan sejenis.

2. Data Sekunder: Data sekunder yang dipergunakan adalah Peta Jaringan Jalan Kota Banjarmasin menuju Martapura (Kelurahan Sungai Lulut) yang bersumber dari citra Google Map.

\section{Waktu Survey}

Survey dilaksanakan selama selama tiga hari yaitu Selasa, Rabu dan Kamis (tanggal 06-08 Februari 2018) dengan periode waktu selama selama dua jam dengan interval waktu per 15 menit pada setiap waktu puncak, yaitu jam sibuk pagi (jam 07.00-09.00 WITA), jam sibuk siang (jam 12.00-14.00 WITA) dan jam sibuk sore (jam 16.0018.00 WITA).

\section{E. Flow Chart Analisis Data}

Flow Chart pelaksanaan penelitian dapat dilihat pada Gambar 2 berikut.

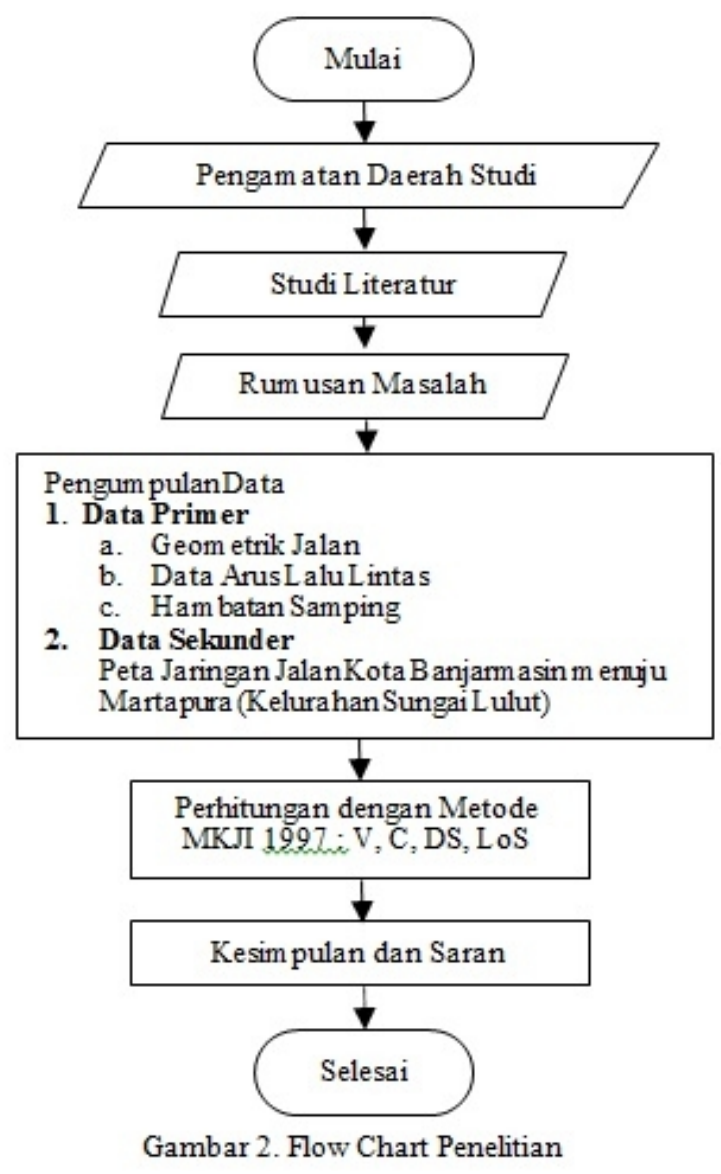

\section{HASIL DAN PEMBAHASAN}

Berikut adalah hasil perhitungan data berdasarkan hasil survey dengan menggunakan metode MKJI.

\section{A. Data Geometrik Jalan Martapura Lama KM 05}

Data geometrik daerah penelitian adalah jalan 2/2 UD dan berstatus Jalan Kabupaten-Jalan Kolektor Primer. Lebar jalur lalu lintas rata-rata (WC) adalah 5 meter dengan lebar bahu efektif (WS), masingmasing 1 meter, tipe perkerasan adalah perkerasan lentur dan alinyemen vertikal tidak ada. 
B. Data Arus Lalu Lintas Per Jam Sibuk Hari Selasa, 06 Februari 2018

Di bawah ini merupakan data perhitungan arus lalu lintas yang diambil pada jam sibuk pagi, jam sibuk siang dan jam sibuk sore, yang dapat dilihat pada Tabel 8 sampai Tabel 10 berikut.
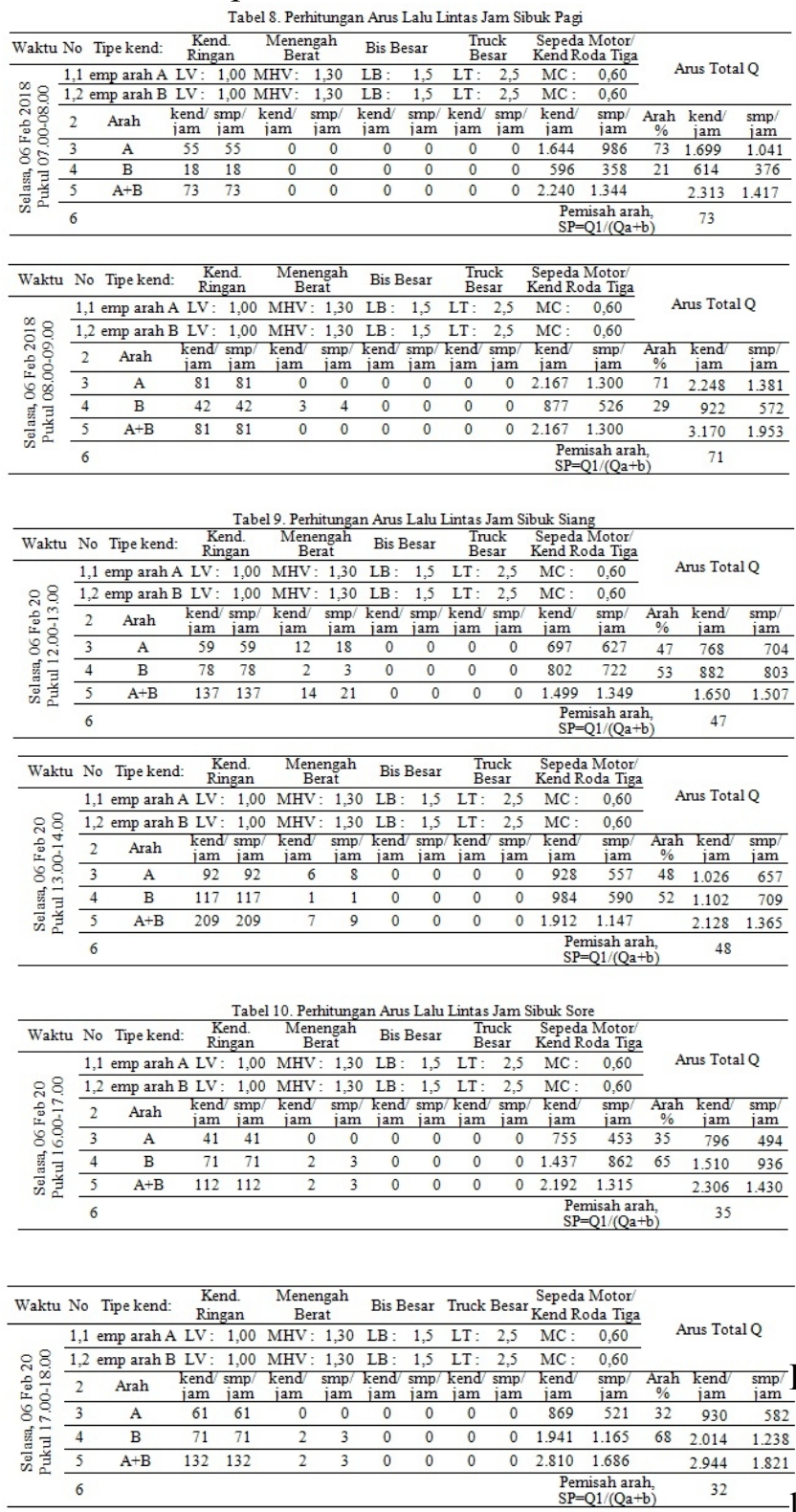

C. Data Arus Lalu Lintas Per Jam Sibuk Hari Rabu, 07 Februari 2018

Di bawah ini merupakan data perhitungan arus lalu lintas yang diambil pada jam sibuk pagi, jam sibuk siang dan jam sibuk sore, yang dapat dilihat pada Tabel 11 sampai 13 berikut.
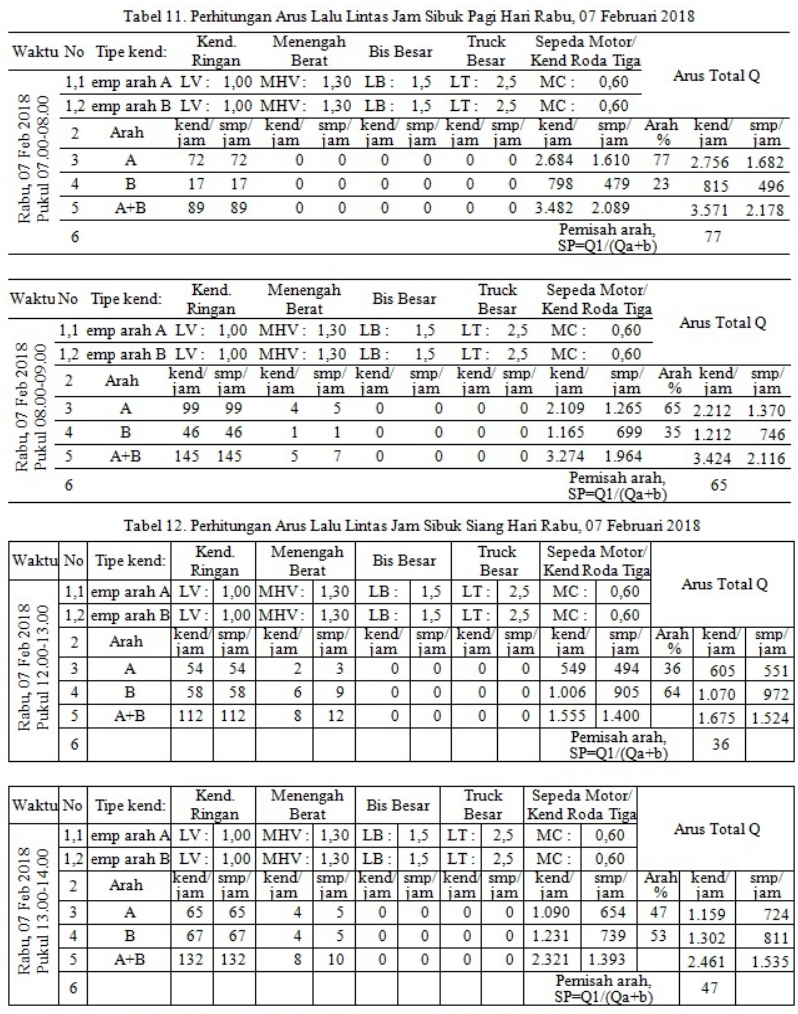
Tabel 13. Perhitungan Arus Lalu Lintas Jam Sibuk Sore Hari Rabu, 07 Februari 2018
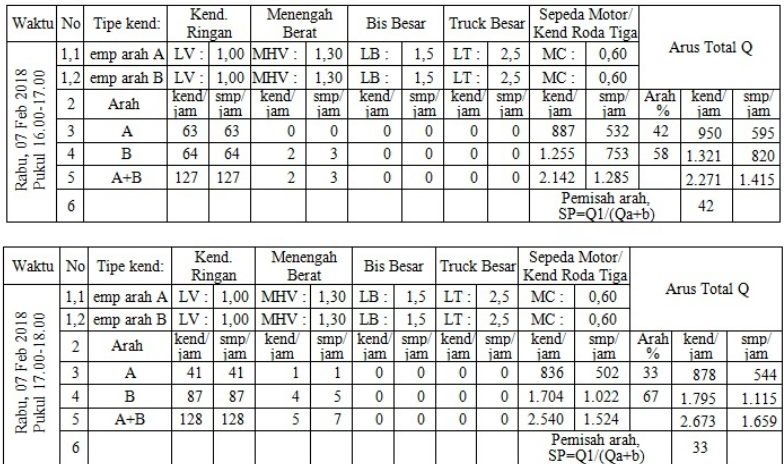

D. Data Arus Lalu Lintas Per Jam Sibuk Hari Kamis, 08 Februari 2018.

Di bawah ini merupakan data perhitungan arus lalu lintas yang diambil pada jam sibuk pagi, jam sibuk siang dan jam sibuk sore, yang dapat dilihat pada Tabel 14 sampai 16 berikut. 


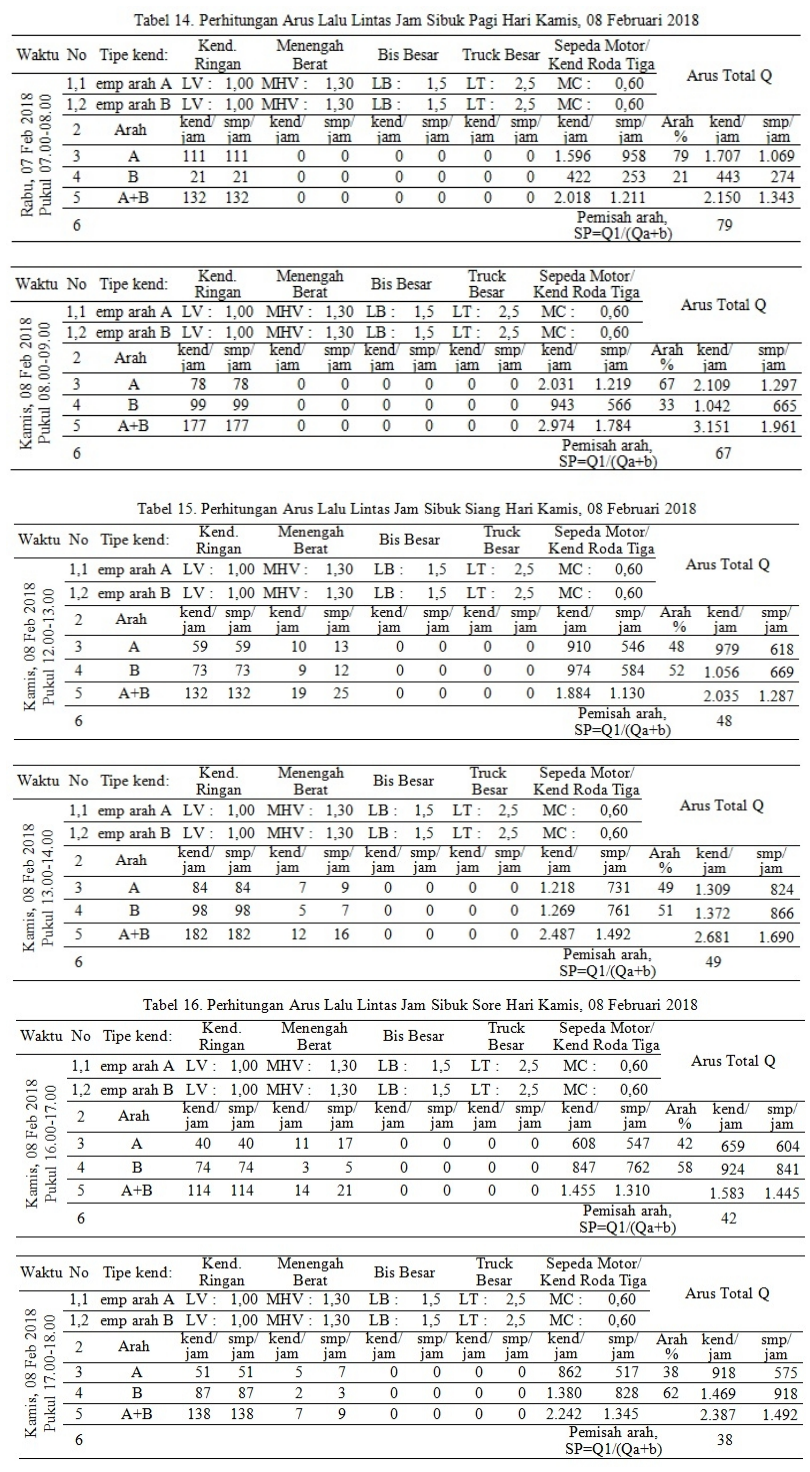

E. Perhitungan Penentuan Kelas Hambatan Samping

Di bawah ini merupakan data frekuensi kejadian hambatan samping per jam per 200 meter segmen yang diamati, yang dapat dilihat pada Tabel 17 sampai Tabel 20. Dan berikut beberapa pengertian dan nilai koefisien untuk hambatan kelas samping, yaitu: $\mathrm{PED}=$ pejalan kaki (bobot 0,6); PSV = penghentian kendaraan umum atau kendaraan lainnya (bobot $=0,8) ; \mathrm{EEV}=$ kendaraan masuk dan keluar lahan di samping jalan (bobot $=1,0)$; SMV = kendaraan lambat (bobot $=0,4) ; \mathrm{LV}=$ sangat rendah; $\mathrm{L}=$ rendah; $\mathrm{M}=$ sedang; $\mathrm{H}=$ tinggi; $\mathrm{VH}=$ sangat tinggi; sisi $\mathrm{A}=$ arah dari Martapura menuju
Banjarmasin; sisi $\mathrm{B}=$ arah dari Banjarmasin menuju Martapura dan frek = frekuensi.
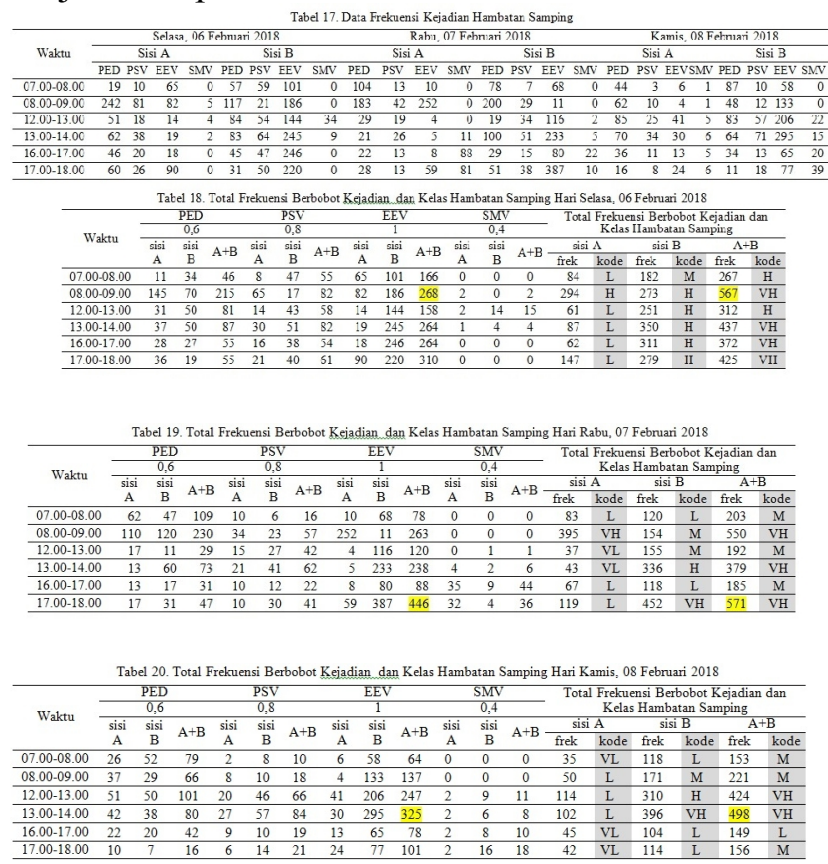

\section{F. Perhitungan Kapasitas}

Di bawah ini merupakan perhitungan kapasitas jalan pada jam sibuk pagi, jam sibuk siang dan jam sibuk sore, Hari Selasa, Rabu dan Kamis, seperti terlihat pada Tabel 21 sampai Tabel 23 berikut.

Tabel 21. Kapasitas Jalan Hari Selasa, 06 Februari 2018

\begin{tabular}{cccccc}
\hline Waktu & $\begin{array}{c}\mathrm{CO} \\
\text { smp/ jam }\end{array}$ & Fcw & FCsp & FCsF & $\begin{array}{c}\mathrm{C} \\
\text { smp/ jam }\end{array}$ \\
\hline $07.00-08.00$ & 3.100 & 0,69 & 0,862 & 0,87 & $1.604,1$ \\
\hline $08.00-09.00$ & 3.100 & 0,69 & 0,874 & 0,83 & $1.551,7$ \\
\hline $12.00-13.00$ & 3.100 & 0,69 & 1,018 & 0,87 & $1.894,4$ \\
\hline $13.00-14.00$ & 3.100 & 0,69 & 1,012 & 0,83 & $1.796,7$ \\
\hline $16.00-17.00$ & 3.100 & 0,69 & 1,090 & 0,83 & $1.935,2$ \\
\hline $17.00-18.00$ & 3.100 & 0,69 & 1,108 & 0,83 & $1.967,1$ \\
\hline
\end{tabular}


Tabel 22. Kapasitas Jalan Hari Rabu, 07 Februari 2018

\begin{tabular}{cccccc}
\hline Waktu & $\begin{array}{c}\mathrm{CO} \\
\text { smp/ jam }\end{array}$ & FCW & FCSP & FCSF & $\begin{array}{c}\mathrm{C} \\
\text { smp/ jam }\end{array}$ \\
\hline $07.00-08.00$ & 3.100 & 0,69 & 0,838 & 0,91 & $1.631,2$ \\
\hline $08.00-09.00$ & 3.100 & 0,69 & 0,910 & 0,83 & $1.615,6$ \\
\hline $12.00-13.00$ & 3.100 & 0,69 & 1,084 & 0,91 & $2.110,0$ \\
\hline $13.00-14.00$ & 3.100 & 0,69 & 1,018 & 0,83 & $1.807,3$ \\
\hline $16.00-17.00$ & 3.100 & 0,69 & 1,048 & 0,91 & $2.039,9$ \\
\hline $17.00-18.00$ & 3.100 & 0,69 & 1,102 & 0,83 & $1.956,5$ \\
\hline
\end{tabular}

Tabel 23. Kapasitas Jalan Hari Kamis 08 Februari 2018

\begin{tabular}{cccccc}
\hline Waktu & $\begin{array}{c}\mathrm{CO} \\
\mathrm{smp} / \mathrm{jam}\end{array}$ & $\mathrm{F}_{\mathrm{CW}}$ & $\mathrm{FC}_{\mathrm{SP}}$ & $\mathrm{FC}_{\mathrm{SF}}$ & $\begin{array}{c}\mathrm{C} \\
\mathrm{smp} / \mathrm{jam}\end{array}$ \\
\hline $07.00-08.00$ & 3.100 & 0,69 & 0,826 & 0,91 & $1.607,8$ \\
\hline $08.00-09.00$ & 3.100 & 0,69 & 0,898 & 0,91 & $1.747,9$ \\
\hline $12.00-13.00$ & 3.100 & 0,69 & 1,012 & 0,83 & $1.796,7$ \\
\hline $13.00-14.00$ & 3.100 & 0,69 & 1,010 & 0,83 & $1.786,0$ \\
\hline $16.00-17.00$ & 3.100 & 0,69 & 1,048 & 0,95 & $2.129,6$ \\
\hline $17.00-18.00$ & 3.100 & 0,69 & 1,072 & 0,91 & $2.086,6$ \\
\hline
\end{tabular}

\section{G. Pembahasan}

Adapun pembahasan yang akan dilakukan dalam penelitian ini adalah mengetahui dampak aktivitas pasar terhadap kinerja ruas Jalan Martapura Lama KM 05 yang ditunjukkan dengan nilai DS (derajat kejenuhan) dan tingkat pelayanan jalannya yang dapat dilihat pada Tabel 24 sampai Tabel 26 berikut.

\begin{tabular}{cccccccc}
\multicolumn{6}{c}{ Tabel 24. Perhitungan Derajat Kejenuhan (DS) Hari Selasa, 06 Februari 2018} \\
\hline Waktu & $\begin{array}{c}\text { Frekuensi } \\
\text { Berbobot } \\
\text { Kejadian }\end{array}$ & $\begin{array}{c}\text { Kelas } \\
\text { Hambatan } \\
\text { Samping }\end{array}$ & $\begin{array}{c}\text { Volume } \\
(\mathrm{Q}) \\
\text { smp/jam }\end{array}$ & $\begin{array}{c}\text { Kapasitas } \\
(\mathrm{C}) \\
\text { smp/jam }\end{array}$ & DS & $\begin{array}{c}\text { Tingkat } \\
\text { Pelayanan }\end{array}$ \\
\hline $07.00-08.00$ & 267 & $\mathrm{H}$ & 1.417 & $1.604,12$ & 0,88 & $\mathrm{D}$ \\
\hline $08.00-09.00$ & 567 & $\mathrm{VH}$ & 1.953 & $1.551,67$ & $\underline{1,26}$ & $\underline{\mathrm{F}}$ \\
\hline $12.00-13.00$ & 312 & $\mathrm{H}$ & 1.507 & $1.894,43$ & 0,80 & $\mathrm{D}$ \\
\hline $13.00-14.00$ & 437 & $\mathrm{VH}$ & 1.365 & $1.796,67$ & 0,76 & $\mathrm{D}$ \\
\hline $16.00-17.00$ & 372 & $\mathrm{VH}$ & 1.430 & $1.935,15$ & $\underline{0,74}$ & $\underline{\mathrm{C}}$ \\
\hline $17.00-18.00$ & 425 & $\mathrm{VH}$ & 1.821 & $1.967,11$ & 0,93 & $\mathrm{E}$ \\
\hline
\end{tabular}

\begin{tabular}{ccccccc}
\multicolumn{7}{c}{ Tabel 25. Perhitungan Derajat Kejenuhan (DS) Hari Rabu, 07 Februari 2018} \\
\hline Waktu & $\begin{array}{c}\text { Frekuensi } \\
\text { Berbobot } \\
\text { Kejadian }\end{array}$ & $\begin{array}{c}\text { Kelas } \\
\text { Hambatan } \\
\text { Samping }\end{array}$ & $\begin{array}{c}\text { Volume } \\
\text { (Q) } \\
\text { smp/jam }\end{array}$ & $\begin{array}{c}\text { Kapasitas } \\
\text { (C) } \\
\text { smp/jam }\end{array}$ & DS & $\begin{array}{c}\text { Tingkat } \\
\text { Pelayanan }\end{array}$ \\
\hline $07.00-08.00$ & 203 & M & 2.178 & $1.631,16$ & $\underline{1,34}$ & $\underline{\text { F }}$ \\
\hline $08.00-09.00$ & 550 & VH & 2.116 & $1.615,59$ & 1,31 & F \\
\hline $12.00-13.00$ & 192 & M & 1.524 & $2.110,00$ & 0,72 & C \\
\hline $13.00-14.00$ & 379 & VH & 1.535 & $1.807,33$ & 0,85 & D \\
\hline $16.00-17.00$ & 185 & M & 1.415 & $2.039,92$ & $\underline{0,69}$ & $\underline{\mathrm{C}}$ \\
\hline $17.00-18.00$ & 571 & VH & 1.659 & $1.956,46$ & 0,85 & D \\
\hline
\end{tabular}

\begin{tabular}{ccccccc}
\hline \multicolumn{7}{c}{ Tabel 26. Perhitungan Derajat Kejenuhan (DS) Hari Kamis, 08 Februari 2018} \\
\hline Waktu & $\begin{array}{c}\text { Frekuensi } \\
\text { Berbobot } \\
\text { Kejadian }\end{array}$ & $\begin{array}{c}\text { Kelas } \\
\text { Hambatan } \\
\text { Samping }\end{array}$ & $\begin{array}{c}\text { Volume } \\
\text { (Q) } \\
\text { smp/jam }\end{array}$ & $\begin{array}{c}\text { Kapasitas } \\
\text { (C) } \\
\text { smp/jam }\end{array}$ & DS & $\begin{array}{c}\text { Tingkat } \\
\text { Pelayanan }\end{array}$ \\
\hline $07.00-08.00$ & 153 & M & 1.343 & $1.607,80$ & 0,84 & D \\
\hline $08.00-09.00$ & 221 & M & 1.961 & $1.747,95$ & $\underline{1,12}$ & $\underline{\text { F }}$ \\
\hline $12.00-13.00$ & 424 & VH & 1.287 & $1.796,67$ & 0,72 & C \\
\hline $13.00-14.00$ & 498 & VH & 1.690 & $1.786,02$ & 0,95 & E \\
\hline $16.00-17.00$ & 149 & L & 1.445 & $2.129,59$ & $\underline{0,68}$ & $\underline{\mathrm{C}}$ \\
\hline $17.00-18.00$ & 156 & M & 1.492 & $2.086,64$ & 0,72 & C \\
\hline & & & & & &
\end{tabular}

Dari tabel diatas, dampak aktivitas pasar terhadap kinerja ruas Jalan Martapura Lama KM 05 yang dinyatakan dengan derajat kejenuhan (DS) dan nilai tingkat pelayanan jalannya adalah sebagai berikut:

1. Pada hari Selasa, 06 Februari 2018; DS paling besar adalah 1,26 dengan tingkat pelayanan adalah $\mathrm{F}$ dan DS paling kecil adalah 0,74 dengan tingkat pelayanan adalah $\mathrm{C}$.

2. Pada hari Rabu, 07 Februari 2018; DS paling besar adalah 1,34 dengan tingkat pelayanan adalah $\mathrm{F}$ dan DS paling kecil adalah 0,69 dengan tingkat pelayanan adalah $\mathrm{C}$

3. Pada hari Kamis, 08 Februari 2018; DS paling besar adalah 1,12 dengan tingkat pelayanan adalah $\mathrm{F}$ dan DS paling kecil adalah 0,68 dengan tingkat pelayanan adalah $\mathrm{C}$.

Jika aktivitas pasar yang menggunakan badan jalan diasumsikan sebagai hambatan samping ditiadakan/ dikurangi sampai nilai minimum dengan frekuensi berbobot dan kejadian (dua sisi) adalah < 50 kejadian (lihat tabel 2), diperoleh kode nilai hambatan samping adalah VL (Very Low). Dengan nilai hambatan samping VL maka nilai Faktor Penyesuaian Kapasitas Akibat Hambatan Samping (FCSF) adalah 0,99 (lihat tabel 6), sehingga kinerja ruas Jalan Martapura Lama KM 05 dengan tanpa adanya hambatan samping yang ditunjukkan dengan nilai DS (derajat kejenuhan) dan tingkat pelayanan jalannya dapat dilihat pada Tabel 27 sampai Tabel 29 berikut.

\begin{tabular}{|c|c|c|c|c|c|}
\hline Waktu & $\begin{array}{l}\text { Kelas Hambatan } \\
\text { Samping }\end{array}$ & $\begin{array}{c}\text { Volume (Q) } \\
\text { smp/jam }\end{array}$ & $\begin{array}{c}\text { Kapasitas (C) } \\
\text { smp/jam }\end{array}$ & DS & $\begin{array}{c}\text { Tingkat } \\
\text { Pelayanan }\end{array}$ \\
\hline U/.UU-U8.UU & VL & 1.417 & $1.825,38$ & 0,78 & $\mathrm{D}$ \\
\hline UX.UU-UY.UU & VL & 1.953 & $1.850,79$ & $\underline{1,06}$ & $\underline{F}$ \\
\hline $12.00-15.00$ & VL & 1.507 & $2.155,73$ & 0,70 & $\mathrm{C}$ \\
\hline $13.00-14.00$ & VL & 1.365 & $2.143,02$ & 0,64 & $\mathrm{C}$ \\
\hline $16.00-1 / .00$ & VL & 1.430 & $2.308,19$ & 0,62 & $\underline{\mathrm{C}}$ \\
\hline $1 / .00-18.00$ & VL & 1.821 & $2.346,31$ & 0,78 & $\mathrm{D}$ \\
\hline \multicolumn{6}{|c|}{ Tabel 28. Perhitungan DS dan Tingkat Pelayanan Hari Rabu, 07 Februari 2018} \\
\hline Waktu & $\begin{array}{l}\text { Kelas Hambatan } \\
\text { Samping }\end{array}$ & $\begin{array}{c}\text { Volume (Q) } \\
\text { smp/jam }\end{array}$ & $\begin{array}{c}\text { Kapasitas (C) } \\
\text { smp/jam }\end{array}$ & DS & $\begin{array}{c}\text { Tingkat } \\
\text { Pelayanan }\end{array}$ \\
\hline $07.00-08.00$ & VL & 2.178 & $1.774,56$ & $\underline{1,23}$ & $\underline{F}$ \\
\hline $08.00-09.00$ & VL & 2.116 & $1.927,03$ & 1,10 & $\mathrm{~F}$ \\
\hline $12.00-13.00$ & VL & 1.524 & $2.295,49$ & 0,66 & $\mathrm{C}$ \\
\hline $13.00-14.00$ & VL & 1.535 & $2.155,73$ & 0,71 & $\mathrm{C}$ \\
\hline $16.00-17.00$ & VL & 1.415 & $2.219,26$ & $\underline{0,64}$ & $\underline{\mathrm{C}}$ \\
\hline $17.00-18.00$ & VL & 1.659 & $2.333,61$ & 0,71 & $\mathrm{C}$ \\
\hline
\end{tabular}


Tabel 29. Perhitungan DS dan Tingkat Pelayanan Hari Kamis 08 Februari 201808 Februari 2018 jam sibuk pagi dengan Total

\begin{tabular}{cccccc}
\hline Waktu & $\begin{array}{c}\text { Kelas Hambatan } \\
\text { Samping }\end{array}$ & $\begin{array}{c}\text { Volume (Q) } \\
\text { smp/jam }\end{array}$ & $\begin{array}{c}\text { Kapasitas (C) } \\
\text { smp/jam }\end{array}$ & DS & $\begin{array}{c}\text { Tingkat } \\
\text { Pelayanan }\end{array}$ \\
\hline $07.00-08.00$ & VL & 1.343 & $1.749,15$ & 0,77 & $\mathrm{D}$ \\
\hline $08.00-09.00$ & VL & 1.961 & $1.901,61$ & $\underline{1,03}$ & $\underline{\mathrm{F}}$ \\
\hline $12.00-13.00$ & VL & 1.287 & $2.143,02$ & $\underline{0,60}$ & $\underline{\mathrm{C}}$ \\
\hline $13.00-14.00$ & VL & 1.690 & $2.130,32$ & 0,79 & $\mathrm{D}$ \\
\hline $16.00-17.00$ & VL & 1.445 & $2.219,26$ & 0,65 & $\mathrm{C}$ \\
\hline $17.00-18.00$ & VL & 1.492 & $2.270,08$ & 0,66 & $\mathrm{C}$ \\
\hline
\end{tabular}

Dari tabel diatas, jika aktivitas pasar pada ruas Jalan Martapura Lama KM 05 dihilangkan, maka nilai derajat kejenuhan (DS) dan nilai tingkat pelayanan jalannya adalah sebagai berikut:

1. Pada hari Selasa, 06 Februari 2018; DS paling besar adalah 1,06 dengan tingkat pelayanan adalah $\mathrm{F}$ dan $\mathrm{DS}$ paling kecil adalah 0,64 dengan tingkat pelayanan adalah $\mathrm{C}$.

2. Pada hari Rabu, 07 Februari 2018; DS paling besar adalah 1,23 dengan tingkat pelayanan adalah $\mathrm{F}$ dan DS paling kecil adalah 0,64 dengan tingkat pelayanan adalah $\mathrm{C}$

3. Pada hari Kamis, 08 Februari 2018; DS paling besar adalah 1,03 dengan tingkat pelayanan adalah $\mathrm{F}$ dan $\mathrm{DS}$ paling kecil adalah 0,60 dengan tingkat pelayanan adalah $\mathrm{C}$.

\section{KESIMPULAN}

Kesimpulan penelitian ini adalah dari tiga hari sampel pengambilan data pada jam sibuk pagi, siang dan sore yaitu Derajat Kejenuhan (DS) terburuk bernilai $\mathrm{F}$ dan Derajat Kejenuhan (DS) terbaik bernilai C. Nilai DS terburuk sebesar 1,34 dengan tingkat pelayanan $\mathrm{F}$ pada jam sibuk pagi hari Rabu, 07 Februari 2018 dan nilai DS terbaik sebesar 0,68 dengan tingkat pelayanan $\mathrm{C}$ pada jam sibuk sore hari Kamis, 08 Februari 2018.

Besarnya pengaruh hambatan samping yaitu pada hari Selasa, 06 Februari 2018 jam sibuk pagi dengan Total Frekuensi Berbobot Kejadian dan Kelas Hambatan Samping sebesar 567 frekuensi, dengan hambatan terbesar adalah kendaraan masuk dan keluar lahan di samping jalan (EEV) sebesar 268 kejadian. Hari Rabu, 07 Februari 2018 jam sibuk pagi dengan Total Frekuensi Berbobot Kejadian dan Kelas Hambatan Samping sebesar 571 frekuensi, dengan hambatan terbesar adalah kendaraan masuk dan keluar lahan di samping jalan (EEV) sebesar 446 kejadian dan pada hari Kamis,
Frekuensi Berbobot Kejadian dan Kelas Hambatan Samping sebesar 498 frekuensi, dengan hambatan terbesar adalah kendaraan masuk dan keluar lahan di samping jalan (EEV) sebesar 325 kejadian. Dari data ini disimpulkan rendahnya tingkat pelayanan jalan disebabkan aktivitas kendaraan masuk dan keluar lahan di samping jalan (EEV) dari dan menuju Pasar Sungai Lulut.

Jika aktivitas pasar yang menggunakan badan jalan diasumsikan sebagai hambatan samping ditiadakan/ dikurangi sampai nilai minimum, nilai DS masih sama, yaitu Derajat Kejenuhan (DS) terburuk bernilai $\mathrm{F}$ dan Derajat Kejenuhan (DS) terbaik bernilai C. Namun terjadi perubahan pada nilai DS, yaitu DS terburuk sebesar 1,23 dengan tingkat pelayanan F pada jam sibuk pagi hari Rabu, 07 Februari 2018 dan nilai DS terbaik sebesar 0,60 dengan tingkat pelayanan $\mathrm{C}$ pada jam sibuk siang hari Kamis, 08 Februari 2018.

\section{UCAPAN TERIMA KASIH}

Terima kasih yang sebesar-besarnya penulis ucapkan kepada saudara Ahmad Saukani yang telah berkontribusi besar dalam pengambilan data yang menunjang artikel ini.

\section{REFERENSI}

Direktorat Jenderal Bina Marga. 1997. Manual Kapasitas Jalan Indonesia. Jakarta.

Funan, Gideon Antoni. Dkk. 2014. Studi Kinerja Jalan Akibat Hambatan Samping di Jalan Timor Raya Depan Pasar Oesao Kabupaten Kupang. Jurnal Teknik Sipil Volume III Nomor 1 April 2014.

Kabupaten Banjar. 2013. Rencana Tata Ruang Wilayah Kabupaten Banjar Tahun 2013 - 2032. Martapura.

Kementerian Perhubungan. 2016. Peraturan Menteri Perhubungan:Manajemen dan Rekayasa Lalu Lintas di Jalan Raya. Jakarta.

Kurniawan, Septyanto. 2015. Analisa Hambatan Samping Akibat Aktivitas Pasar Modern (Studi Kasus pada Jalan Brigjen Katamso di Bandar Lampung). TAPAK Volume 5 Nomor 1 November 2015. 
Prasetyo, Fikhry.Dkk. ......Kajian Manajemen Lalu Lintas Sekitar Kawasan Pasar Singosari

Kabupaten Malang. Fakultas Teknik Universitas Brawijaya. Malang.

Rohman, Muhammad Atho'ur dan Dwi Kartikasari. 2016. Analisa Kemacetan Lalu Lintas pada Pasar Tradisional di Ruas Jalan SekaranMaduran. Jurnal CIVILLa Volume 1 Nomor 2 September 2016.

Tampubolon, Rudolf Eric. 2012. Analisis Pengaruh Pasar Tradisional Terhadap Kinerja Ruas Jalan Studi Kasus Jalan Medan-Binjai KM 9 Pasar Kp. Lalang. Tugas Akhir Mahasiswa. Universitas Sumatra Utara. Medan.

Tamin, Ofyas. 2000. Perencanaan dan Permodelan Transportasi. Institut Teknologi Bandung. Bandung.

Salleh, Arbillah. Dkk. ..... . Kajian Manajemen Lalu Lintas Sekitar Kawasan Pasar dan Ruko Lawang Kabupaten Malang. Fakultas Teknik Universitas Brawijaya. Malang.

Syahputra, Randy. Dkk. 2015. Pengaruh Hambatan Samping Terhadap Kinerja Lalu Lintas Jalan Nasional (Studi Kasus Jalan Proklamator RayaPasar Bandarjaya Plaza). Jurnal Rekayasa Sipil dan Desain, edisi September 2015 Volume 3 Nomor 3 tahun 2015. 